\title{
Low-resistivity $\alpha$-phase tungsten films grown by hot-wire assisted atomic layer deposition in high-aspect-ratio structures
}

\author{
Mengdi Yang*, Antonius A.I. Aarnink, Jurriaan Schmitz, Alexey Y. Kovalgin \\ MESA + Institute for Nanotechnology, University of Twente, P.O. Box 217, 7500 AE Enschede, The Netherlands
}

\section{A R T I C L E I N F O}

\section{Keywords:}

Hot wire

Tungsten

ALD

Alpha-phase

Low resistivity

High-aspect-ratio substrates

\begin{abstract}
A B S T R A C T
In this work, the so-called hot-wire (HW) assisted atomic layer deposition (HWALD) technique is employed to grow high-purity $\alpha$-phase tungsten (W) films at a substrate temperature of $275^{\circ} \mathrm{C}$. The films are deposited on thermally grown silicon dioxide $\left(\mathrm{SiO}_{2}\right)$ in a home-built hot-wall reactor, using alternating pulses of $\mathrm{WF}_{6}$ and $\mathrm{HW}$ generated atomic hydrogen in the self-limiting surface-reaction manner characteristic for ALD. A W seed layer, needed to enable the HWALD-W process on a $\mathrm{SiO}_{2}$ surface, is formed prior to each deposition. In-situ spectroscopic ellipsometry is used to monitor the growth behavior and film properties. The films exhibit a high-purity (99 at.\%) W, according to X-ray photoelectron spectroscopy. The X-ray diffraction scans reveal the existence of $\alpha$-phase W. The resistivity measurements by means of four point probe, transfer length method test structures and the Drude-Lorentz SE model all reveal a low resistivity of $15 \mu \Omega \cdot \mathrm{cm}$. The high-resolution transmission electron microscopy analysis shows a uniform and conformal coverage of high aspect ratio structures, confirming the effective ALD process and the sufficient diffusion of both $\mathrm{WF}_{6}$ and at- $\mathrm{H}$ into deep trenches.
\end{abstract}

\section{Introduction}

Many studies have dealt with the deposition of metallic thin films for application in semiconductor devices $[1,2]$. In today's metallization schemes, tungsten (W) vias are widely used to provide inter-level contacts between metal layers [1]. Tungsten can conventionally be deposited by chemical vapor deposition (CVD) or by sputtering $[3,4]$. However, the downscaling of device dimensions and the increase of the scale of integration pose stringent demands on the W-film conformity, uniformity and especially the step coverage in high aspect ratio (HAR) structures. In this light, atomic layer deposition (ALD), due to its selflimiting reaction mechanism [5], is rapidly strengthening its position as a method suitable for industrial use [6].

ALD of $\mathrm{W}$ has been reported by using $\mathrm{WF}_{6}$ and different reductants, for example, disilane [7-10], silane [11,12] and $\mathrm{B}_{2} \mathrm{H}_{6}$ [12,13]. The reductants form an intermediate sacrificial layer (i.e. silicon (Si) or boron (B), respectively), which can be turned into $\mathrm{W}$ while reacting with $\mathrm{WF}_{6}$. However, deposition of $\mathrm{Si}$ or $\mathrm{B}$ in those cases is hardly limited to 1-monolayer (ML) formation, thereby diminishing the self-limiting nature of ALD. It may additionally leave $\mathrm{Si}, \mathrm{B}$ and fluorine (F) impurities inside the films, resulting in a higher-resistivity $\mathrm{W}$ [13].

For ALD of metals, a common approach is to utilize plasma-enhanced ALD (PEALD) [6]. However, a plasma can cause damage to the wafer through high-energy ions and UV light [14]. In addition, a plethora of radicals and ions can be created by a plasma, enabling numerous side-reactions often deteriorating the film quality and complicating process control.

Hot-wire ALD (HWALD) is emerging alternative technique that has the potential to overcome the mentioned limitations of PEALD, while still enabling the formation of reactive species (radicals) at low substrate temperatures. This technically-easier approach employs a filament that is heated up to a temperature in the range $1300-2000{ }^{\circ} \mathrm{C}$ to dissociate precursor molecules. Recently, this method has been utilized for ALD of metals such as tungsten (W), nickel (Ni) and cobalt (Co) [15-19].

It is well known that molecular hydrogen $\left(\mathrm{H}_{2}\right)$, when it comes in contact with a tungsten wire at a temperature above $1300{ }^{\circ} \mathrm{C}$, can catalytically dissociate into atomic hydrogen (at-H) [20-22]. Importantly, the hot wire (HW) itself is not a source of tungsten: the W vapor pressure is rather low at temperatures below $2000{ }^{\circ} \mathrm{C}$. Therefore the filament is not an efficient source of W. Previously, our group has reported on HWALD of $\mathrm{W}$ films in a cold-wall reactor using $\mathrm{WF}_{6}$ gas and HW-generated at-H pulses $[15,16]$. Despite the high purity (approx. 98 at.\%), the deposited $\mathrm{W}$ occurred in $\beta$-phase [1] possessing a resistivity of $\sim 100 \mu \Omega \cdot \mathrm{cm}$. In this work, we demonstrate high-purity $\alpha$ phase [1] W films with a much lower resistivity of $15 \mu \Omega \cdot \mathrm{cm}$, deposited by HWALD in a hot-wall reactor. Significantly, the films can be deposited in trenches with an aspect ratio of 36 and a trench width of

\footnotetext{
* Corresponding author

E-mail address: M.Yang@utwente.nl (M. Yang).
} 
$30 \mathrm{~nm}$.

\section{Methods}

\subsection{Deposition set-up}

The details of our home-built hot-wall reactor used for all depositions can be found elsewhere [23-26]. This 24-ml hot-wall inner reactor is placed inside a big (several liters) cold-wall outer reactor. The system is equipped with an in-situ Woollam M-2000 spectroscopic ellipsometer (SE) operating in the wavelength range between 245 and $1688 \mathrm{~nm}$, combined with CompleteEASE software. The SE enables monitoring of the deposition process in real time. The HW is installed on the side, $2-3 \mathrm{~cm}$ away from the wafer. Importantly, there is no direct line-ofsight between the hot wire and the substrate. Temperature of the filament (hot wire) was determined using the known temperature coefficient of resistance (TCR) of bulk W and further verified by a pyrometer. During a HWALD process, the temperature was maintained constantly by applying fixed voltage to the filament. According to the required duration of at-H pulse, either fixed $\mathrm{H}_{2}$ - or Ar-flow along the filament was maintained. Change of the gas ambient for the filament resulted in the variation of its temperature within $2-3 \%$, as estimated from the current fluctuations. When molecular hydrogen $\left(\mathrm{H}_{2}\right)$ is introduced via this heated wire, it can catalytically dissociate into at- $\mathrm{H}$, forming the first precursor. The second precursor $\left(\mathrm{WF}_{6}\right)$ is supplied via the lateral gas inlets distributed around the substrate. It is essential to confirm that $\mathrm{WF}_{6}$ does not come in contact with the hot filament, thereby generating a flux of $\mathrm{W}$-containing radicals to the wafer surface. We had therefore performed special experiments (see ref. [15]) where the $\mathrm{H}_{2}$ flow along the hot filament was permanently replaced by Ar flow, while keeping standard $\mathrm{WF}_{6}$ flow to the substrate. As a result, no measurable growth of $\mathrm{W}$ was detected, excluding the back-stream diffusion of $\mathrm{WF}_{6}$ to the hot filament and its subsequent decomposition. Although at- $\mathrm{H}$ has to make a 90-degree turn in order to reach the substrate, there is still an appreciable flux of at-H to the wafer surface, as earlier confirmed by Te etching experiments [24]. The pressure was maintained by a turbo pump equipped with a throttle valve.

\subsection{Deposition of HWALD tungsten films}

The tungsten thin films were deposited on top of $100 \mathrm{~nm}$ silicon dioxide $\left(\mathrm{SiO}_{2}\right)$ thermally grown on p-type $\mathrm{Si}(100)$ wafers. Prior to deposition, the wafers were cleaned in fuming (99\%) $\mathrm{HNO}_{3}$ and boiling $69 \% \mathrm{HNO}_{3}$ to remove organic and metallic contaminations, respectively. Then the substrates were immersed in $0.3 \%$ HF solution for $3 \mathrm{~min}$. To circumvent the very slow nucleation of tungsten on $\mathrm{SiO}_{2}$ [27], a W seed layer of an average thickness from 2 to $5 \mathrm{~nm}$ was preformed on $\mathrm{SiO}_{2}$ at a substrate temperature of $325^{\circ} \mathrm{C}$. This included two steps: (i) growing a few-nm-thin amorphous $\mathrm{Si}$ (a-Si) layer using trisilane gas and (ii) subsequently exposing the a-Si to $\mathrm{WF}_{6}$ gas, forming a solid $\mathrm{W}$ film and volatile silicon fluorides. The details about the seed layer formation can be found elsewhere $[15,16]$. There is no fundamental limitation to the thickness of the HWALD W film as the process occurs with a constant growth rate and can be continued for a long time. We had grown up to $20 \mathrm{~nm}$ in this work because there was no need for growing thicker films.

The HWALD $\mathrm{W}$ films were grown using sequential $\mathrm{WF}_{6}$ and at- $\mathrm{H}$ pulses at substrate temperatures ranging between 220 and $350{ }^{\circ} \mathrm{C}$, and total pressures between 0.3 and $50 \mathrm{~Pa}$. The temperature of the hot wire was set at $1750{ }^{\circ} \mathrm{C}$. The flow rates of $\mathrm{WF}_{6}$ and $\mathrm{H}_{2}$ were fixed at $3 \mathrm{sccm}$ and $50 \mathrm{sccm}$, respectively; an Ar purge of $50 \mathrm{sccm}$ was introduced in between the precursor pulses. The pulse and purge durations were optimized to find the HWALD window. Finally, an approximately 10nm-thick capping layer of a-Si was deposited on top of HWALD W, to prevent tungsten oxidation in air after sample unloading.

Besides planar $\mathrm{SiO}_{2}$ substrates, HAR Si pillars and $\mathrm{Al}_{2} \mathrm{O}_{3}$-coated $\mathrm{Si}$ trenches were used to examine the step coverage of HWALD W. On the pillars, the HWALD process was directly started without the seed layer formation; whereas the seed layer was first formed on the $\mathrm{Al}_{2} \mathrm{O}_{3}$-covered substrates. Due to the narrow trenches (aspect ratio (AR) up to 36), the a-Si thickness for the seed layer was reduced to $0.5 \mathrm{~nm}$ in this case. Further, no a-Si capping layer was applied to the HAR structures after HWALD.

\subsection{Ex-situ analysis}

The film thickness at the wafer center was measured real-time by SE during each deposition experiment. For thickness mapping, ex-situ SE was employed. The thickness was verified by high-resolution scanning electron microscopy (HR-SEM) [15] and high-resolution transmission electron microscopy (HR-TEM) for 10-nm-thick layers. The optical functions of HWALD W were obtained by SE and parameterized using a Drude-Lorentz description consisting of a Drude term and two Lorentz oscillators, where the resistivity can be extracted from the Drude term $[28,29]$. In the SE models, it was possible to distinguish between properties of the W seed layer and HWALD W film grown on top of the seed layer. In the text below, when not mentioned explicitly, "HWALD" refers only to the W film deposited by HWALD on top of the seed layer. To note, the SE data additionally allow to reliably obtain the film crystallinity (i.e. either $\alpha$ - or $\beta$-phase), without the need for an external $\mathrm{X}$-ray diffraction (XRD) analysis [25].

The crystallinity was measured by X-ray diffraction (XRD) with a PANalytical X'PERT MPD diffractometer. The XRD patterns were recorded in a $\theta-2 \theta$ scan mode for $2 \theta=34-90^{\circ}$ using $\mathrm{Cu} \mathrm{K} \alpha$ radiation. The film surface morphology was characterized by a Bruker Fastscan/ICON atomic force microscope (AFM) in tapping mode. The film composition was obtained by X-ray photoelectron spectroscopy (XPS) using a PHI Quantera SXM spectrometer. The X-ray source irradiation was set at $\mathrm{Al}$ $\mathrm{K} \alpha$ line with an energy of $1486.6 \mathrm{eV}$. A Multipak software was used for data processing. All peak positions in the XPS spectra were calibrated with respect to the known reference binding energy of aliphatic carbon $\mathrm{C} 1 \mathrm{~s}$ at $284.8 \mathrm{eV}$.

\subsection{Resistivity measurement}

In addition to the SE measurements, the resistivity was electrically measured with an automatic Polytec four point probe (FPP) stage for blanket films. Furthermore, Transfer Length Method (TLM) [30] test structures were realized to measure $\mathrm{W}$ resistivity in the thickness range $0.65-5 \mathrm{~nm}$. The TLM (also called Shockley method [31]) allows to reliably obtain contact and sheet resistances by measuring the potential difference between pairs of contacts at a given applied current and plotting this as a function of the pair distance. Two masks were applied: (i) defining Pt electrodes by lift-off and (ii) patterning both the HWALD $\mathrm{W}$ and capping a-Si layers by conventional photolithography and etching. The TLM fabrication details can be found in the previous work that focused on the properties of titanium nitride thin films [32,33]. To note, all the layers (including the $\mathrm{W}$ seed layer) were deposited on the pre-formed Pt electrodes. To etch a-Si at room temperature, HF (50\%), $\mathrm{HNO}_{3}(69 \%)$ and deionized $\mathrm{H}_{2} \mathrm{O}$ were mixed at 1:50:40 ratios, respectively; W was patterned in a $31 \% \mathrm{H}_{2} \mathrm{O}_{2}$ solution at $50{ }^{\circ} \mathrm{C}$. The TLM structures were characterized using a Karl-Suss PM8 probe station and a Keithley 4200 semiconductor characterization system.

\section{Results and discussion}

\subsection{HWALD window}

The precursor exposure and purge times are the key parameters determining the ALD window. A properly-tuned ALD process reveals self-limiting surface reactions, leading to a time-independent growth rate per cycle (GPC). As shown in Fig. 1 (a), the GPC sharply increased 


\section{a}

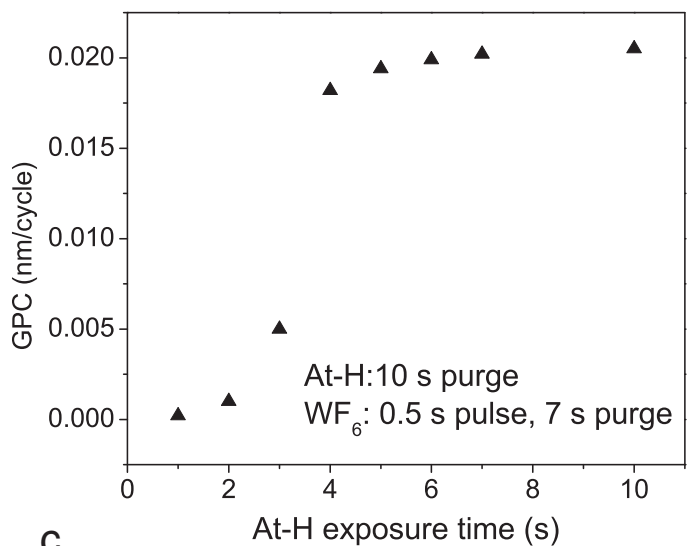

$\mathrm{b}$
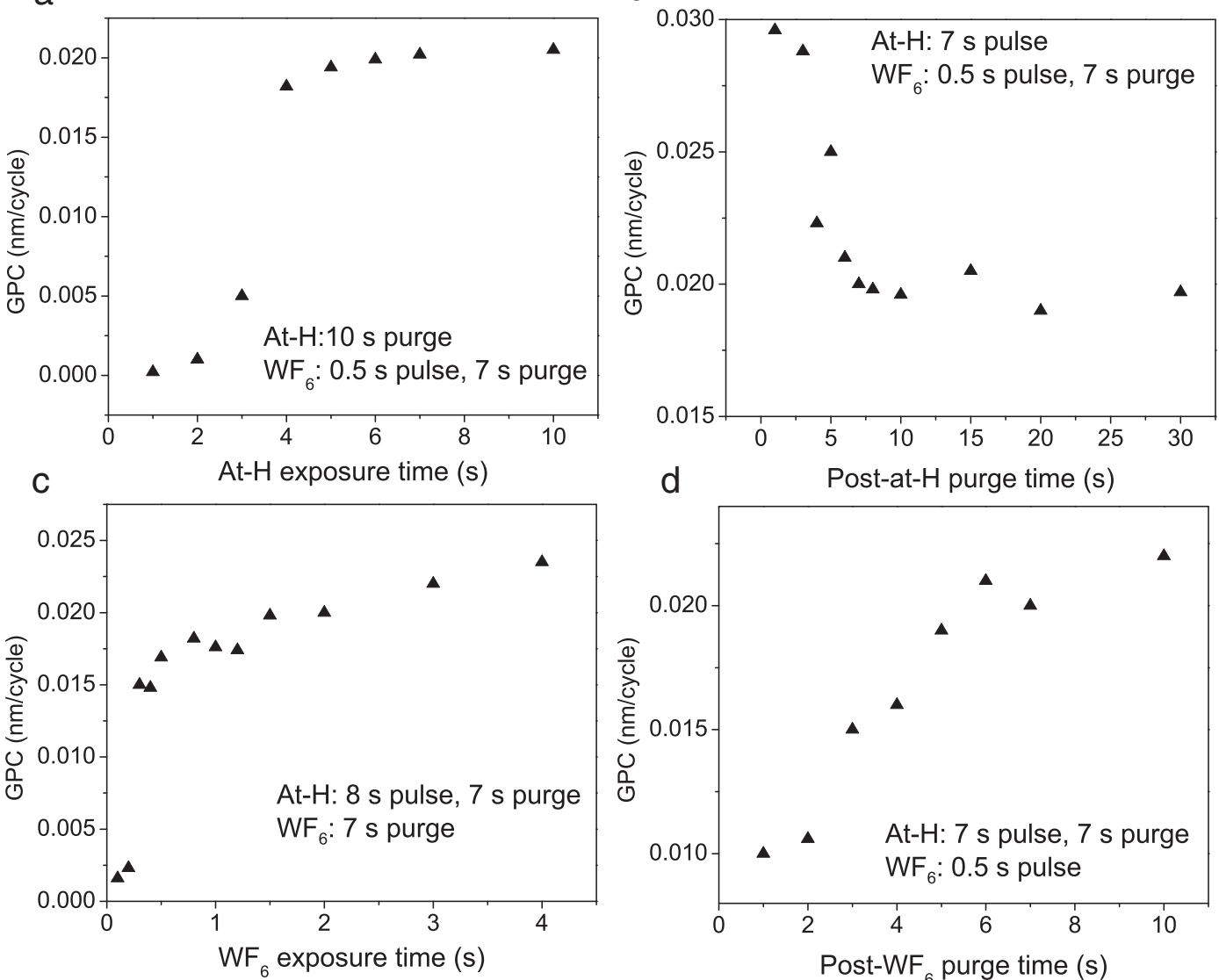

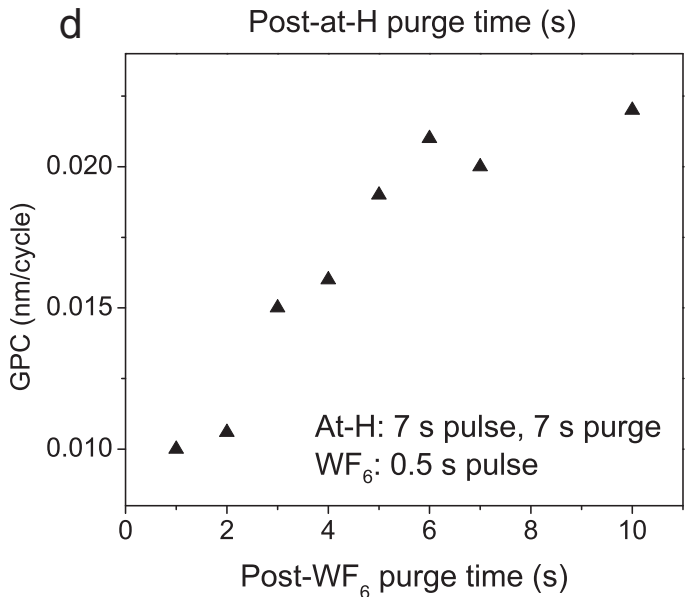

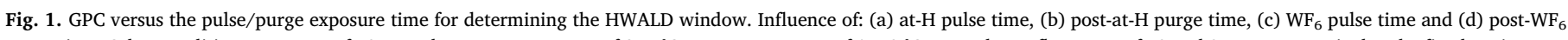

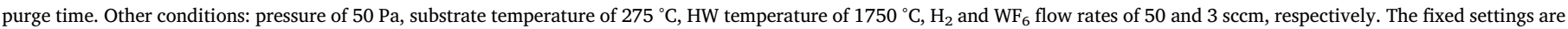
shown in the legend of each graph.

with the at-H exposure time rising from 2 to $4 \mathrm{~s}$, and remained constant for the exposures longer than $6 \mathrm{~s}$. With respect to the post-at-H purge time, the GPC stabilized for the exposures longer than $6 \mathrm{~s}$ (Fig. 1 (b)), pointing to the efficient removal of at-H prior to each $\mathrm{WF}_{6}$ pulse and thus avoiding CVD reactions. Fig. 1 (c) and (d) further illustrates the influence of the pulse- and purge-time of $\mathrm{WF}_{6}$. The GPC was only slightly influenced by $\mathrm{WF}_{6}$ pulse times from $0.3 \mathrm{~s}$ to $2 \mathrm{~s}$. The GPC however started growing as the pulse time was longer than $2 \mathrm{~s}$, presumably due to an incomplete removal of $\mathrm{WF}_{6}$ by the 7 -s purge step, thus causing CVD. Also, the GPC gradually increased as the post- $\mathrm{WF}_{6}$ purge time exceeded $2 \mathrm{~s}$, as shown in Fig. 1 (d). A shorter post-WF 6 purge time was inadequate to remove all $\mathrm{WF}_{6}$, leading to a strong suppression of the GPC by the co-existent etching of the deposited W film [15]. The increase of net GPC, while going from 2 to $7 \mathrm{~s}$ of the post$\mathrm{WF}_{6}$ purge time, is therefore related to the diminishing contribution of etching. The latter is due to the better removal of $\mathrm{WF}_{6}$ from the reaction chamber. Based on Fig. 1, a standard HWALD cycle was chosen to consist of a $7 \mathrm{~s}$ pulse of at-H followed by a $0.5 \mathrm{~s}$ pulse of $\mathrm{WF}_{6}$. An $\mathrm{Ar}$ purge of $7 \mathrm{~s}$ was introduced in between the precursor pulses.

The as-defined ALD window represents the GPC behavior under clean-reactor conditions. Although the GPC was reasonably independent of the pulse/purge durations within the as-defined ALD window, its absolute value could still vary between 0.01 and $0.021 \mathrm{~nm} /$ cycle from experiment to experiment. This means that the practicallyobtained GPC effectively depended on the pre-deposition history. Performing a large number of experiments without efficient cleaning steps of the chamber from the residual $\mathrm{WF}_{6}$ or fluorine after each experiment led to overall lowering of the GPC. This presumably occurred due to the etching of the deposited $\mathrm{W}$ film by fluorine-containing compounds mentioned above. As elaborated in our previous work [15], such compounds can likely adsorb on non-heated parts of the reaction chamber, interfering with the deposition process and resulting in a memory effect. Their background pressure can finally prohibit the film growth, making etching dominant over deposition.

To limit the memory effect, the overall $\mathrm{WF}_{6}$ dose has to be minimized. Fig. 2 illustrates the influence of $\mathrm{WF}_{6}$ over-dose on the growth rates. When the $\mathrm{WF}_{6}$ flow rate increased from $3 \mathrm{sccm}$ (standard recipe) to $10 \mathrm{sccm}$, the GPC gradually reduced from 0.02 to $0.01 \mathrm{~nm} /$ cycle with increasing the pulse time (Fig. 2 (a)). Moreover, with this flow rate, a linear growth (i.e., constant GPC) could only be maintained for $60 \mathrm{cy}$ cles: the GPC decreased afterwards upon the accumulation of $\mathrm{WF}_{6}$ in the chamber (Fig. 2 (b)). In our previous work [15] HWALD W was deposited in a cold-wall reactor. This led to excess background pressure of fluorine-containing compounds and possibly resulted in the growth of $\beta$-phase W. Employing a hot-wall reactor in this work presumably enabled $\alpha$-phase $\mathrm{W}$ (see further sections). To note, etching was much less prominent in the hot-wall reactor, given that the flow rate of $\mathrm{WF}_{6}$ was limited to $3 \mathrm{sccm}$. Lowering the net GPC due to etching can for example be seen in Fig. 1 (d) while shortening the post-WF $\mathrm{WF}_{6}$-purge pulses.

The GPC variations with substrate temperature $\left(T_{\mathrm{s}}\right)$ are presented in Fig. 3 (a). Only a weak dependence is observed for $T_{s}>275^{\circ} \mathrm{C}$. Furthermore, the GPC hardly depends on the total process pressure in the range from 1 to $50 \mathrm{~Pa}$ (Fig. 3 (b)). To avoid the mentioned accumulation of fluorine-containing species and thus minimize the parasitic etch effect, a total pressure of $50 \mathrm{~Pa}$ was chosen for the HWALD-W process.

Based on these findings, the standard HWALD conditions were fixed for further experiments at a substrate temperature of $275^{\circ} \mathrm{C}$ and a 
a

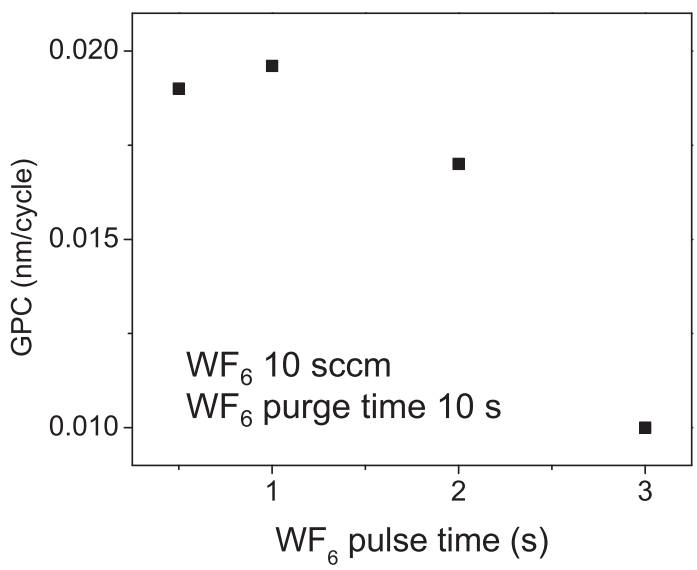

b

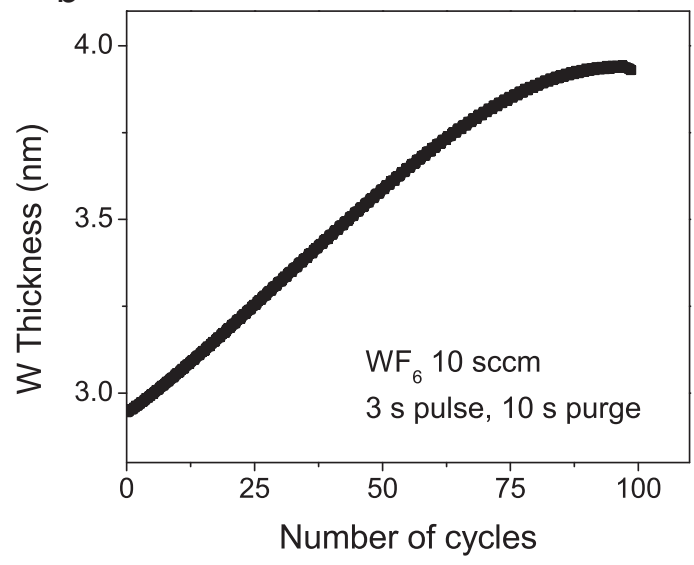

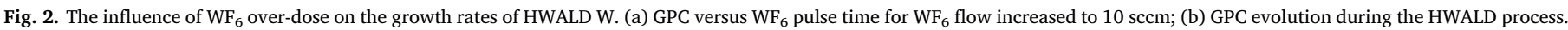

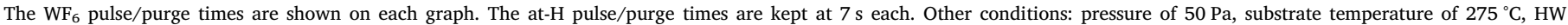
temperature of $1750{ }^{\circ} \mathrm{C}$, and $\mathrm{H}_{2}$ flow rate of $50 \mathrm{sccm}$.

a

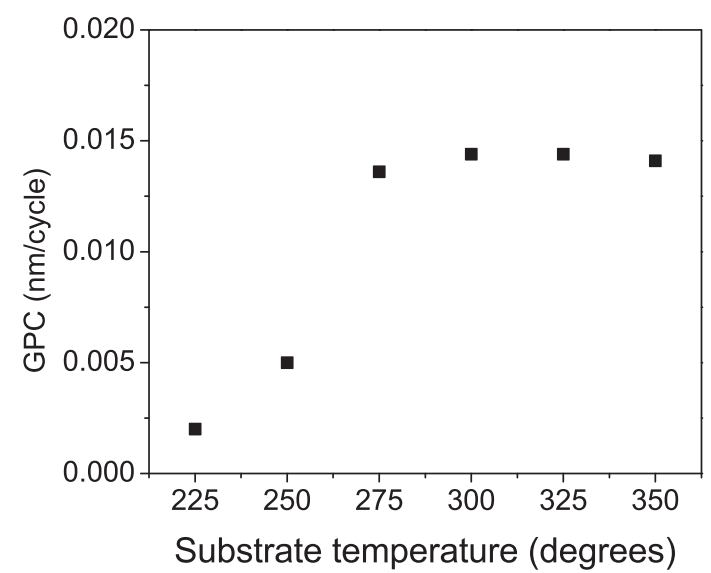

b

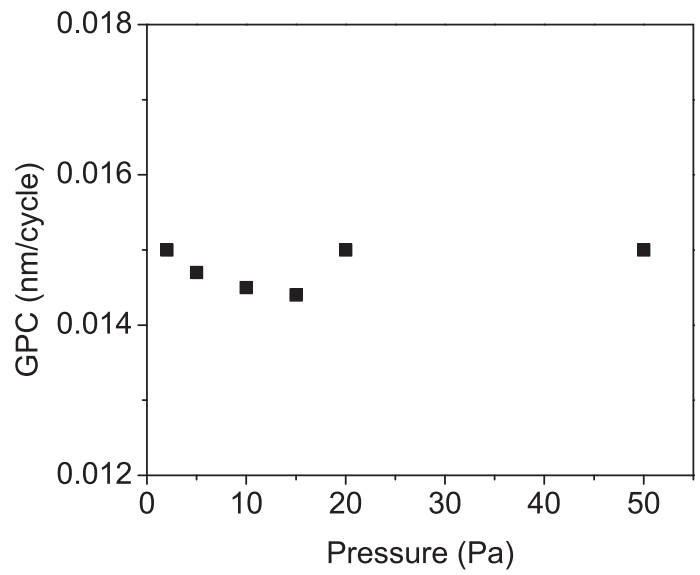

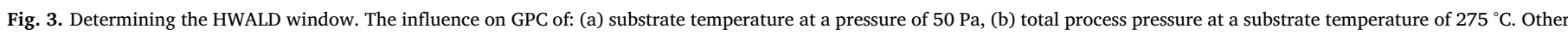
conditions: $\mathrm{HW}$ temperature of $1750{ }^{\circ} \mathrm{C}$, standard pulse durations, $\mathrm{H}_{2}$ and $\mathrm{WF}_{6}$ flow rates of 50 and $3 \mathrm{sccm}$, respectively.

a

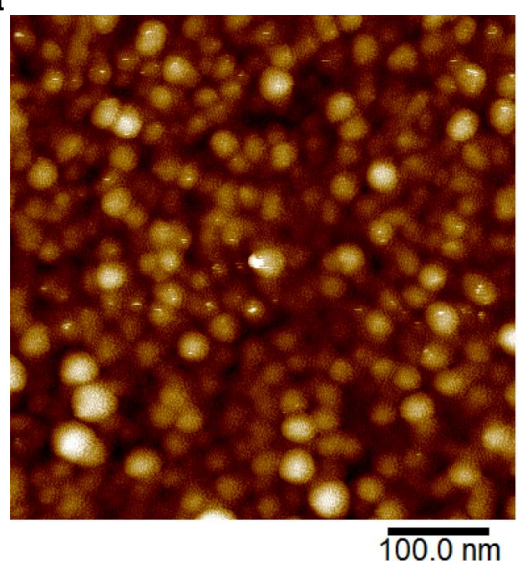

b

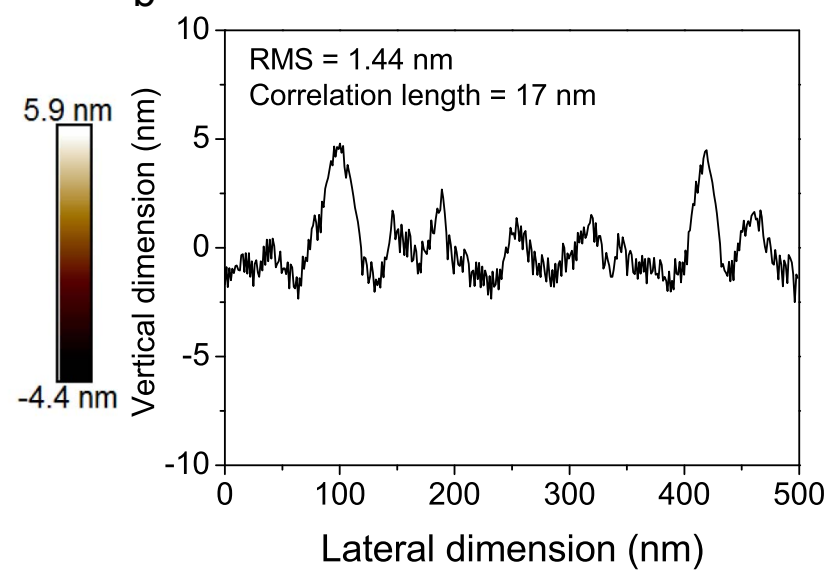

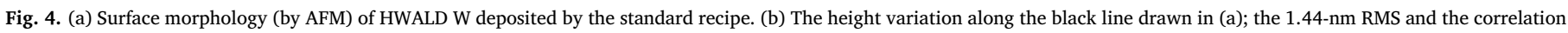
length of $17 \mathrm{~nm}$ were extracted by Nanoscope Analysis software. 


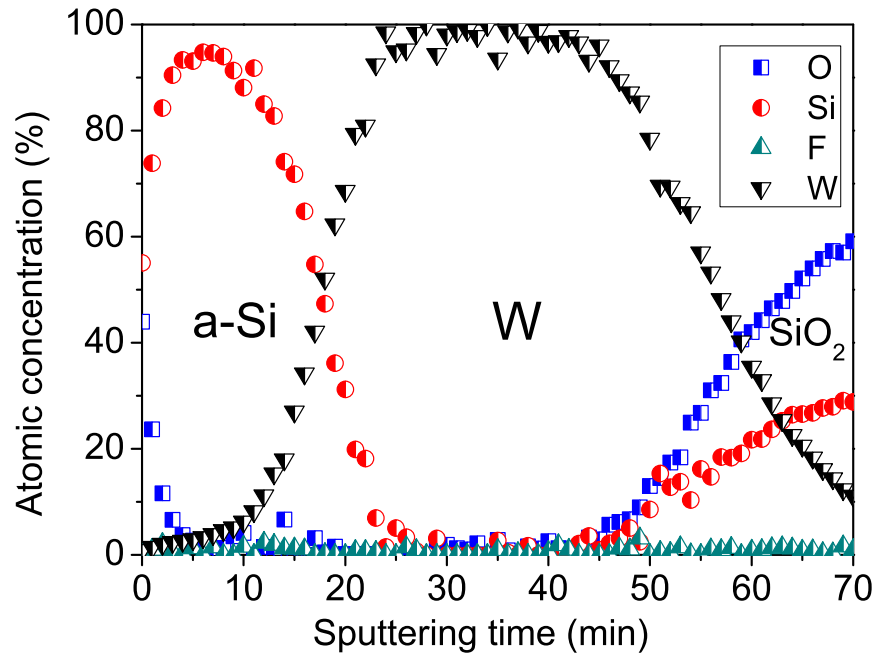

Fig. 5. Compositional XPS depth profile of an HWALD W film grown by the standard deposition recipe.

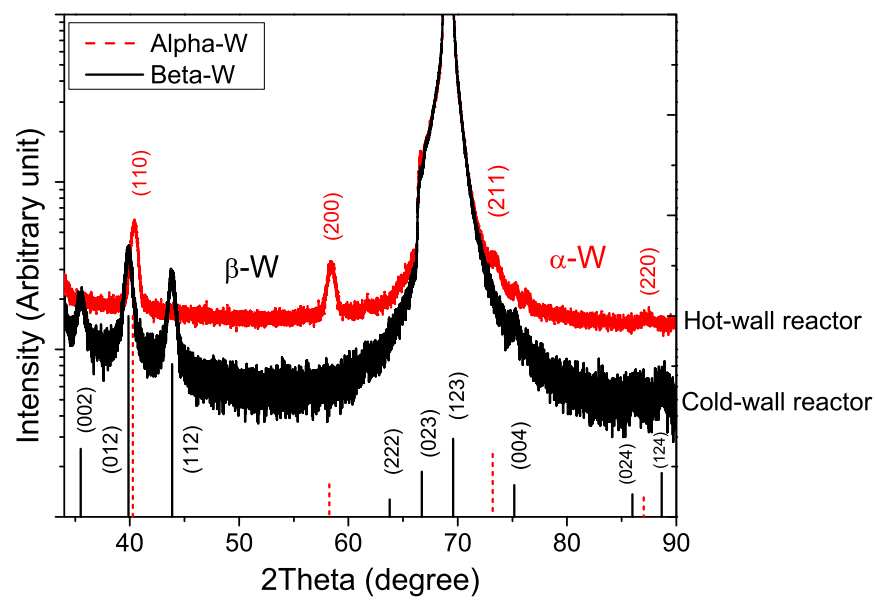

Fig. 6. A comparison of typical XRD patterns of HWALD W films deposited in two different reactor configurations. The diffraction peak positions and the crystal planes of $\alpha$ and $\beta$-phases are shown by the corresponding vertical lines $[1,34,43]$.

a

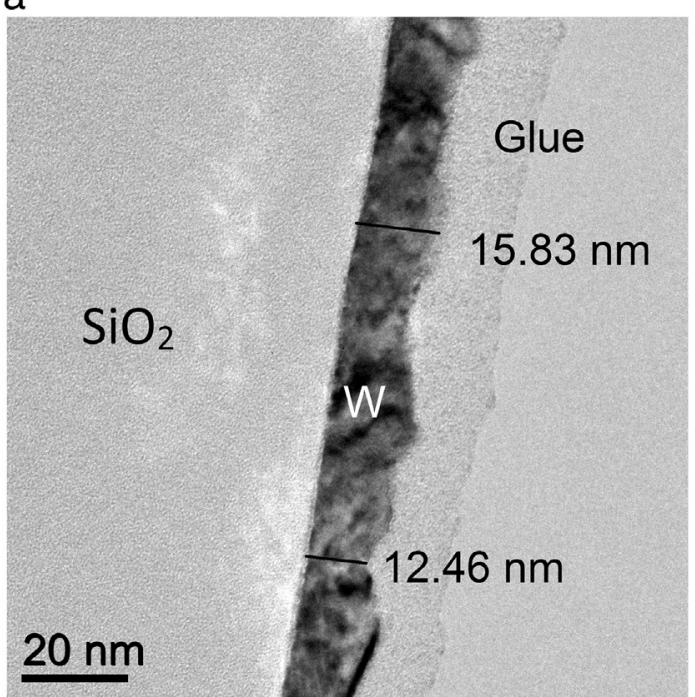

total pressure of $50 \mathrm{~Pa}$. Each ALD cycle consisted of $0.5-\mathrm{s}-\mathrm{WF}_{6}$ and 7-sat-H pulses with the corresponding 7-s-Ar purges in between. The flow rates of $\mathrm{H}_{2}$ and $\mathrm{WF}_{6}$ were kept at 50 and $3 \mathrm{sccm}$, respectively. The wire temperature was kept at $1750{ }^{\circ} \mathrm{C}$, consistent with our previous experiments [15].

\subsection{Surface roughness and film composition}

In our earlier work [16], the reported root mean square (RMS) roughness of a standard W seed layer and an a-Si capping layer revealed the values of 1.67 and $0.02 \mathrm{~nm}$, respectively. Fig. 4 shows the surface morphology and roughness of a 9-nm-thick HWALD tungsten film obtained in this work. The RMS of $1.44 \mathrm{~nm}$ is comparable with that of the seed layer, indicating that the seed layer is the main contributor to the total roughness. The maximum thickness variation is $8.2 \mathrm{~nm}$ according to Fig. 4.

A typical XPS sputter-depth profile of an HWALD W film is shown in Fig. 5. The layers of a-Si (capping), deposited $\mathrm{W}$ and underlying $\mathrm{SiO}_{2}$ can be clearly identified. Oxygen was only found at the surface of the capping layer. The fluorine signal was below the detection limit through the entire film thickness, indicating an efficient removal of $\mathrm{F}$ by at-H. The high concentration of W, reaching 99 at.\%, revealed the highpurity W deposited by HWALD.

\subsection{Crystallinity}

Tungsten is known to exist in $\alpha, \beta$ and $\gamma$ crystal phases [34,35]. Among them, $\alpha$ is the most stable phase; $\beta$-phase is metastable and is normally formed by $\mathrm{W}_{3} \mathrm{~W}$ or $\mathrm{W}_{3} \mathrm{O}$ clusters $[36,37]$. Moreover, $\beta$-phase can be transformed into $\alpha$-phase by annealing above $600{ }^{\circ} \mathrm{C}[38,39]$. Finally, $\gamma$-phase has only been found at the beginning of sputtering and can readily recrystallize into $\alpha-\mathrm{W}[1]$. $\alpha-\mathrm{W}$ possesses a body centered cubic lattice with a lattice constant of $0.316 \mathrm{~nm}$ [40], whereas $\beta$-phase has a cubic $A_{3} B$ (A 15) crystal structure with a lattice constant of $0.504 \mathrm{~nm}$ [41]. Bulk $\beta$-phase $\mathrm{W}$ is known to possess a higher resistivity, normally above 100 and up to $1290 \mu \Omega \cdot \mathrm{cm}[36,37,42]$, compared to $5.6 \mu \Omega \cdot \mathrm{cm}$ of bulk $\alpha$-phase W [1].

The XRD patterns of $\mathrm{W}$ films deposited by HWALD in two different (i.e., cold-wall versus hot-wall) reactor configurations are compared in Fig. 6. To note, only crystals with crystal planes oriented parallel to the substrate can be observed by a $\theta-2 \theta$ scan. The strongest peak at around $69^{\circ}$ corresponds to the $\mathrm{Si}(100)$ substrate. This intense peak overlaps

b

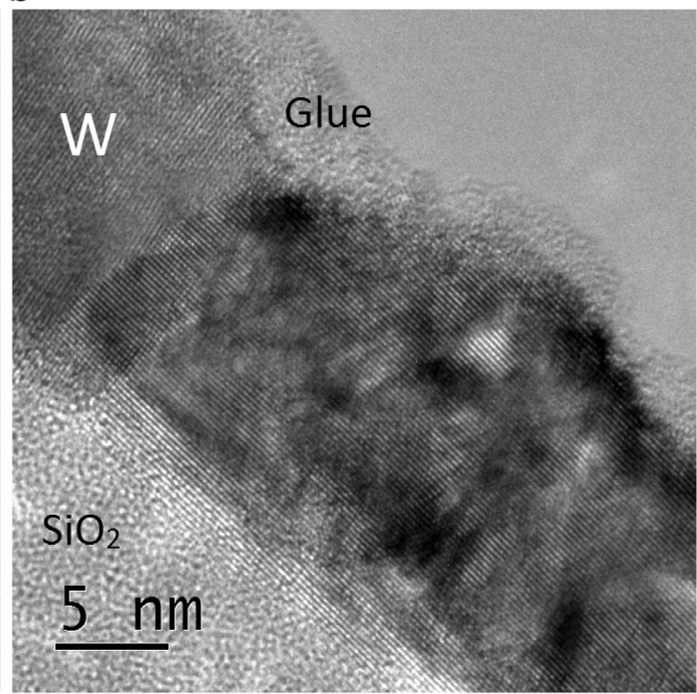

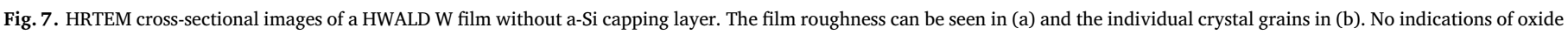
formation were found. 
a

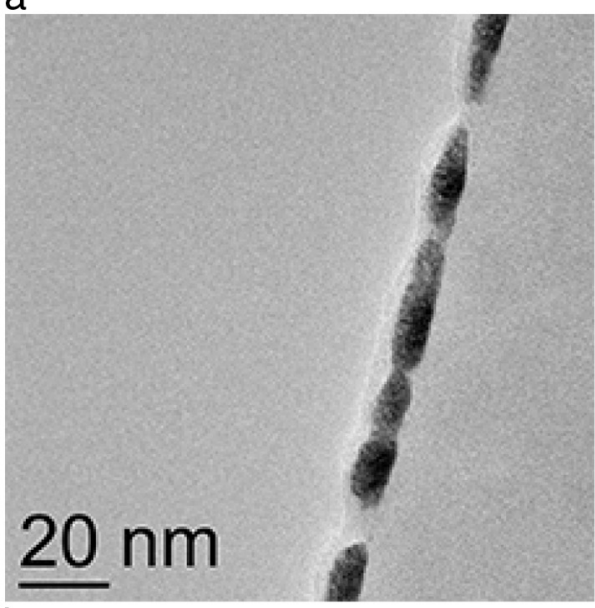

b

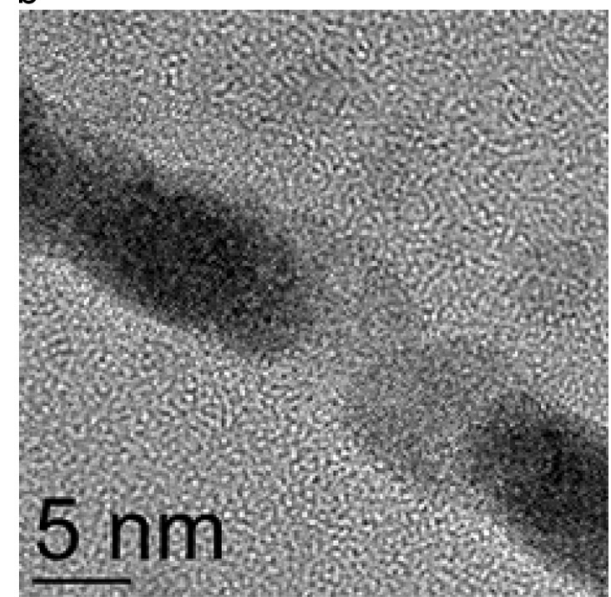

C

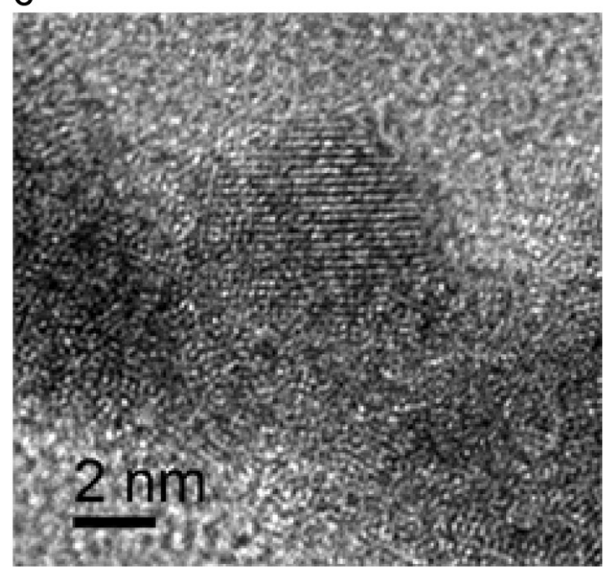

Fig. 8. HRTEM cross-sectional images of a pre-formed $\mathrm{W}$ seed layer. The film discontinuity can be seen in (a) and the crystallinity in (b) and (c).

with the three peaks of $\beta$ phase in the range of $60^{\circ}-70^{\circ}$, making them invisible. The four distinguishable peaks, unique for the $\alpha$-phase [34], are located at $40.2^{\circ}\left((110)\right.$ plane), $58.2^{\circ}$ ((200) plane), $73.2^{\circ}$ ((211) plane $)$ and $87.1^{\circ}((220)$ plane $)$. The peaks of $\beta-\mathrm{W}$ are located at $35.5^{\circ}$ ((002) plane), $39.8^{\circ}$ ((012) plane), $43.8^{\circ}$ ((112) plane), $86.2^{\circ}$ ((024) plane) and $88.7^{\circ}((124)$ plane) $[1,43]$. From Fig. 6 , it can be concluded that only the peaks of $\alpha$-phase are present in the HWALD W of the hotwall reactor, whereas only the peaks of $\beta$-phase $W$ appear in the coldwall reactor films. Apparently, with the same precursors and deposition methods used, the film crystallinity depends on the actual hardware configuration. a
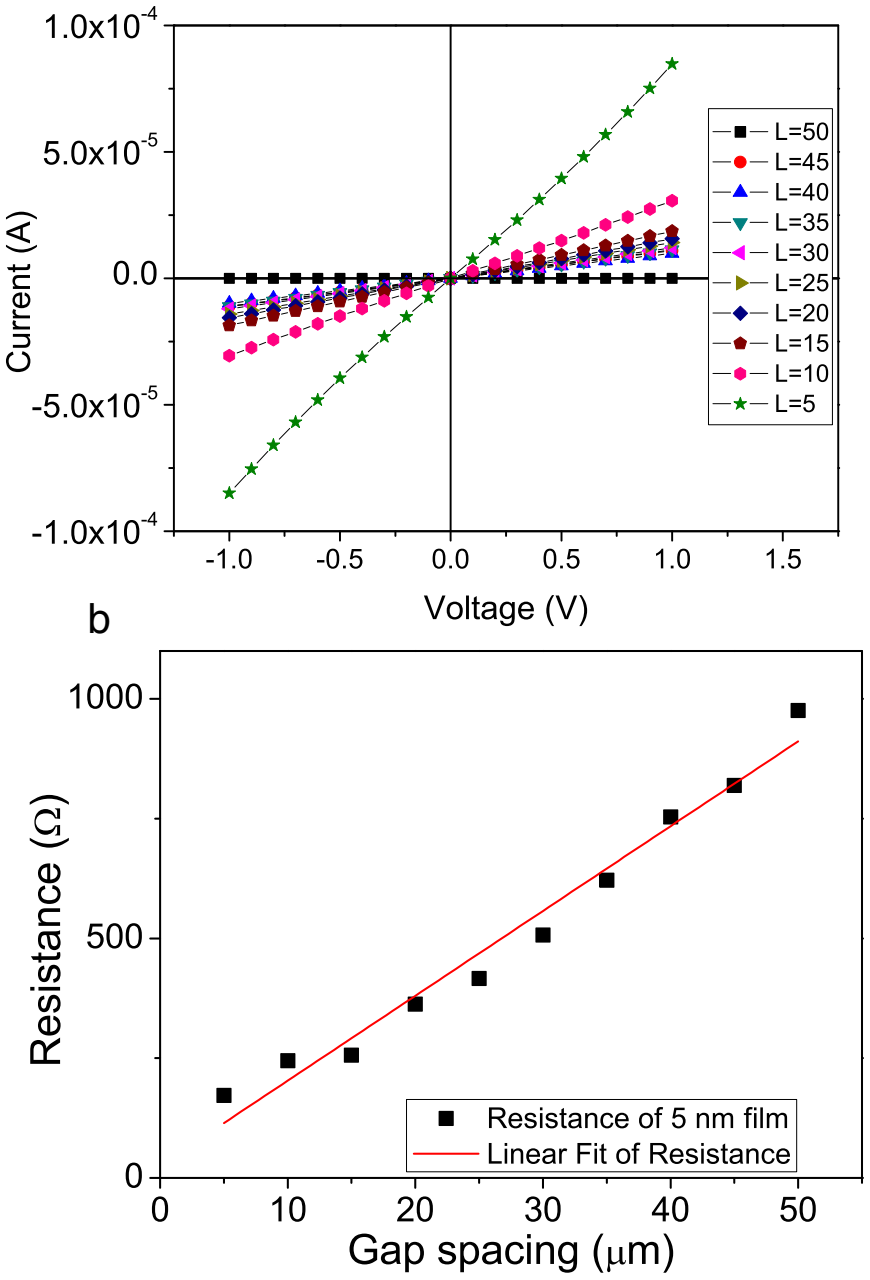

Fig. 9. (a) I-V curves measured by means of TLM on a $0.9 \mathrm{~nm}$ HWALD $\mathrm{W}$ film for various gap spacing $L$ between two Pt electrodes. (b) The extracted total resistance $R$ versus $L$ for a $5 \mathrm{~nm}$ HWALD W film.

The lattice constants of both $\alpha$ - and $\beta$-phases have been calculated from the diffraction peak positions shown in Fig. 6 . The values reveal $0.505 \pm 0.001 \mathrm{~nm}$ for the cold-wall reactor film and $0.315 \pm 0.001 \mathrm{~nm}$ for the hot-wall reactor $\mathrm{W}$. These values are consistent with the lattice constants reported for the $\alpha$ - and $\beta$-phases in the literature. Furthermore, the crystal grain sizes were evaluated by HighScore Plus software, using Scherrer's equation [44]. The calculated grains ranged in size from 5.2 to $10.3 \mathrm{~nm}$ and from 10 to $32 \mathrm{~nm}$ for the cold-wall and hot-wall reactor films, respectively.

Cross-sectional HRTEM images of a hot-wall HWALD W film without a-Si capping layer are presented in Fig. 7. (To avoid any confusion: if not mentioned explicitly in the text, all HWALD W films discussed in the remainder of this article were deposited in the hot-wall reactor.) In Fig. 7 (a), a rough film can be observed with the film thickness varying between 12 and $16 \mathrm{~nm}$. The individual crystal grains of the same film are shown in Fig. 7 (b) at a higher magnification. The visual grain size can be estimated at approximately $20 \mathrm{~nm}$. The $d$-spacing values obtained by reduced Fast-Fourier transform method are 0.220 and $0.157 \mathrm{~nm}$, corresponding to $\alpha-\mathrm{W}$ [1]. Remarkably, the analysis reveals only pure-W (i.e., no oxygen) crystals in the film bulk, even without any protection by the capping a-Si layer. This indicates a weak and slow oxidation of the HWALD W film in air.

The cross-sectional HRTEM images of a pre-formed W seed layer are depicted in Fig. 8. Different from the continuous film in Fig. 7 (a), the W 


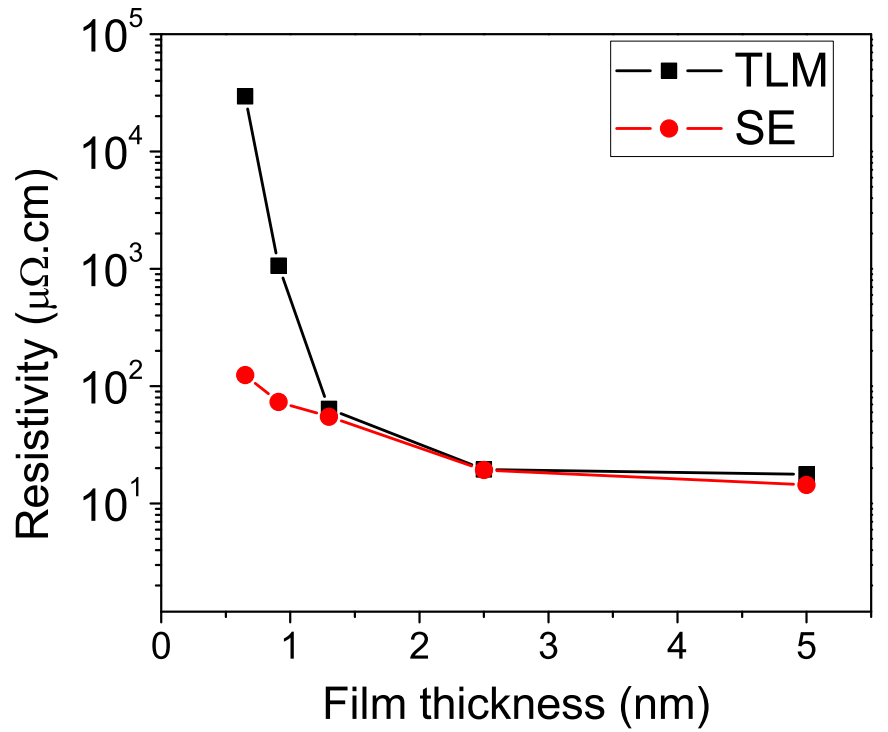

Fig. 10. A comparison of the resistivity obtained by optical (SE, red circles) and electrical (TLM, black squares) methods. To note, the SE measurements were carried out at a substrate temperature of $275{ }^{\circ} \mathrm{C}$, whereas the TLM measurements were performed at room temperature. (For interpretation of the references to color in this figure legend, the reader is referred to the web version of this article.)

seed layer consists of separated clusters with a thickness varying between 1 and $6 \mathrm{~nm}$. As XRD could not provide reliable information on the seed layer crystallinity due to the small thickness, the crystal grains were evaluated with HRTEM, as shown in Fig. 8 (b) and (c). In most film areas, the W clusters were dominantly amorphous. A few crystallites were however found (see Fig. 8 (c)) with $d$-spacing values of 0.228 , $0.135 \mathrm{~nm}, 0.216$ and $0.186 \mathrm{~nm}$. While the first two values correspond to $\beta-W$, the latter two likely indicate tungsten oxide [45]. Despite the differences in crystallinity between the seed layer and the HWALD W layer formed on top of it, no clear interface between these two layers can be detected in Fig. 7 (b). This implies that crystallinity of the seed layer can likely turn into $\alpha$-phase during the subsequent HWALD step.

\subsection{Resistivity and uniformity}

Resistivity of W films was measured (i) electrically by the FPP method, (ii) electrically by means of TLM structures and (iii) optically by using the Drude-Lorentz SE model. While the entire film thickness (i.e., including the seed layer) is probed by FPP, SE allows to obtain resistivity solely of the HWALD layer by building a proper model. The FFP measurements on a $9 \mathrm{~nm}$ HWALD W film (plus a $4 \mathrm{~nm}$ seed layer) revealed a resistivity of $15 \mu \Omega \cdot \mathrm{cm}$. The SE analysis, solely applied to the same HWALD film produced a very similar value, consistent with $\alpha-W$. It has been reported that the lowest resistivity obtained for CVD W, grown at $400{ }^{\circ} \mathrm{C}$ from $\mathrm{WF}_{6}$ and $\mathrm{H}_{2}$ precursors, can vary between 8 and $18 \mu \Omega \cdot \mathrm{cm}$ [1]. Therefore, the HWALD W possesses a remarkably low resistivity, competing with that of CVD W. One can further emphasize the small film thickness and the reduced process temperature in our case. To bear in mind, all HWALD W films earlier deposited in the coldwall reactor possessed $\beta$-phase and a higher resistivity of $100 \mu \Omega \cdot \mathrm{cm}$ [16], upon the same seed layer. Moreover, the smaller grain size of the $\beta$-phase films implies a larger number of grain boundaries per unit film area. This can also contribute to their higher electrical resistivity compared to the $\alpha$-phase $\mathrm{W}$.

The TLM resistivity measurements were carried out for several HWALD-W film thicknesses: 0.65, 0.9, 1.3, 2.5 and $5 \mathrm{~nm}$. All the films were passivated by highly-resistive a-Si capping layers, which exhibited a non-linear conduction, orders of magnitude lower compared to that of the W films. Fig. 9 (a) represents linear current-voltage (I-V) curves of

\section{a}
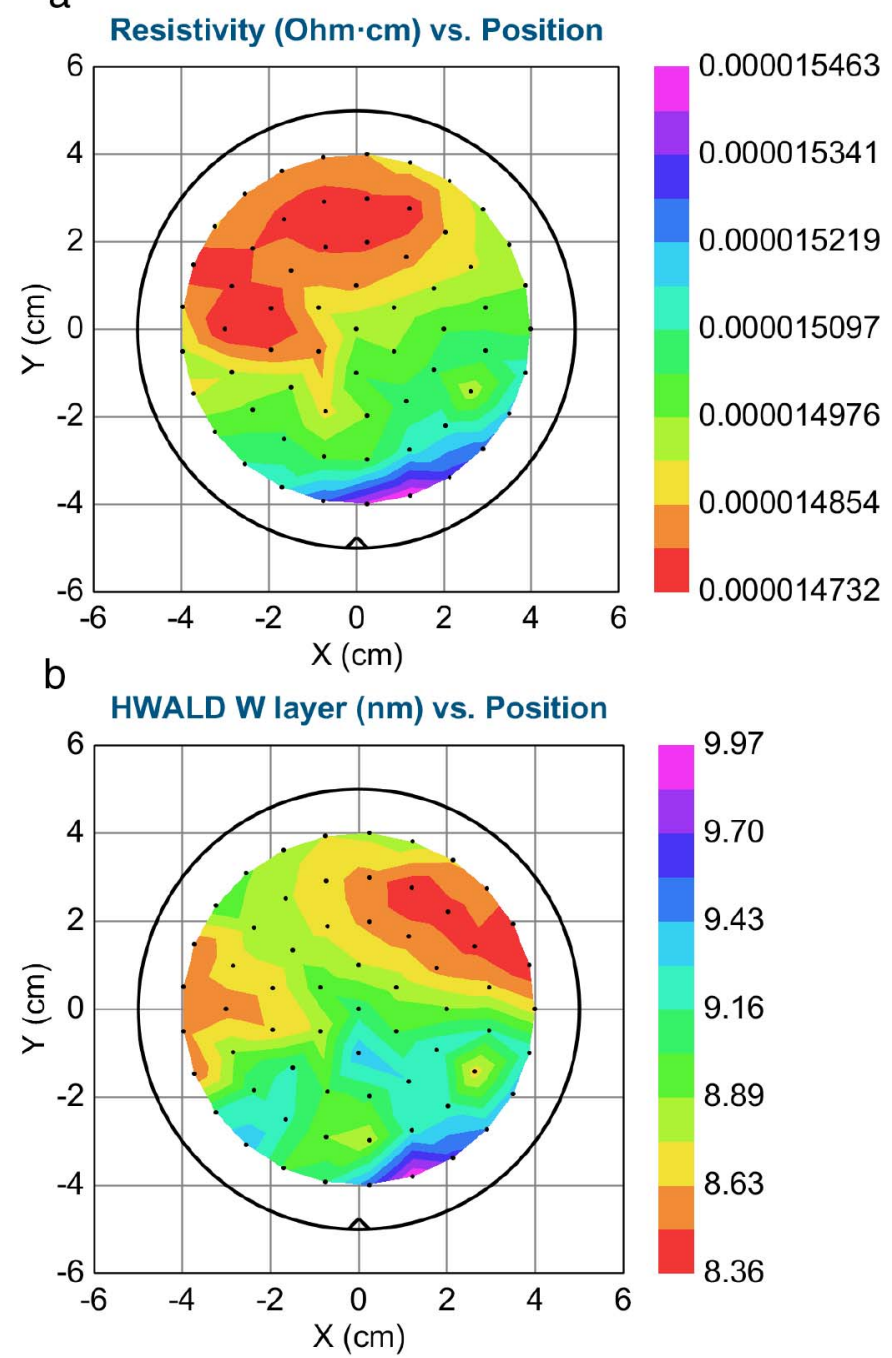

Fig. 11. (a) Resistivity and (b) thickness mapping of a HWALD W film deposited at standard conditions.

the $0.9-\mathrm{nm}$ film on a standard $\mathrm{W}$ seed layer. Such linear behavior was observed for all thicknesses, indicating well-established current paths in the films and an ohmic contact between the W film and the Pt contact pads. The resistance of only the seed layer equaled the capping layer resistance, thereby confirming the earlier conclusion that the $\mathrm{W}$ islands seen in Fig. 8 (a) were hardly connected to each other. After growing the 0.65-nm HWALD film on top of the seed layer, the electrical conductance was significantly increased, suggesting the dominant contribution of this film to the conductivity. Fig. 9 (b) shows the total resistance $(R)$ as a function of gap spacing $(L)$ for the thickest 5-nm film on the seed layer. A sheet resistance of $17 \Omega / \square$ can be obtained from the slope of this linear fit. Calculating the resistivity reveals $17 \mu \Omega \cdot \mathrm{cm}$, taking the thicknesses of both seed and HWALD W layer into account.

Likewise, the resistivity for all five film thicknesses was calculated (see Fig. 10) and compared with the values extracted from in-situ SE measurements. To note, the SE resistivity was measured at a substrate temperature of $275^{\circ} \mathrm{C}$, whereas the TLM measurements were carried out at room temperature. Our previous work [46] performed for ultrathin TiN films showed only a little disagreement between SE resistivity values measured for the same film at room temperature and at $350{ }^{\circ} \mathrm{C}$. For the films shown in Fig. 10, one can see a good agreement between the electrically- and optically-measured resistivity for the thicknesses exceeding $1.3 \mathrm{~nm}$. However, for the thinner films, the electrical resistivity is orders of magnitude higher than the corresponding optical 
a

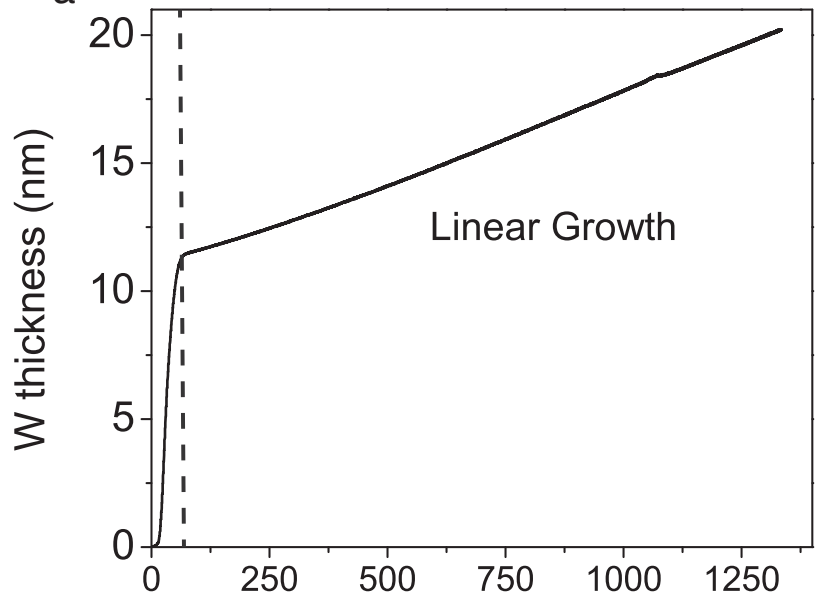

b
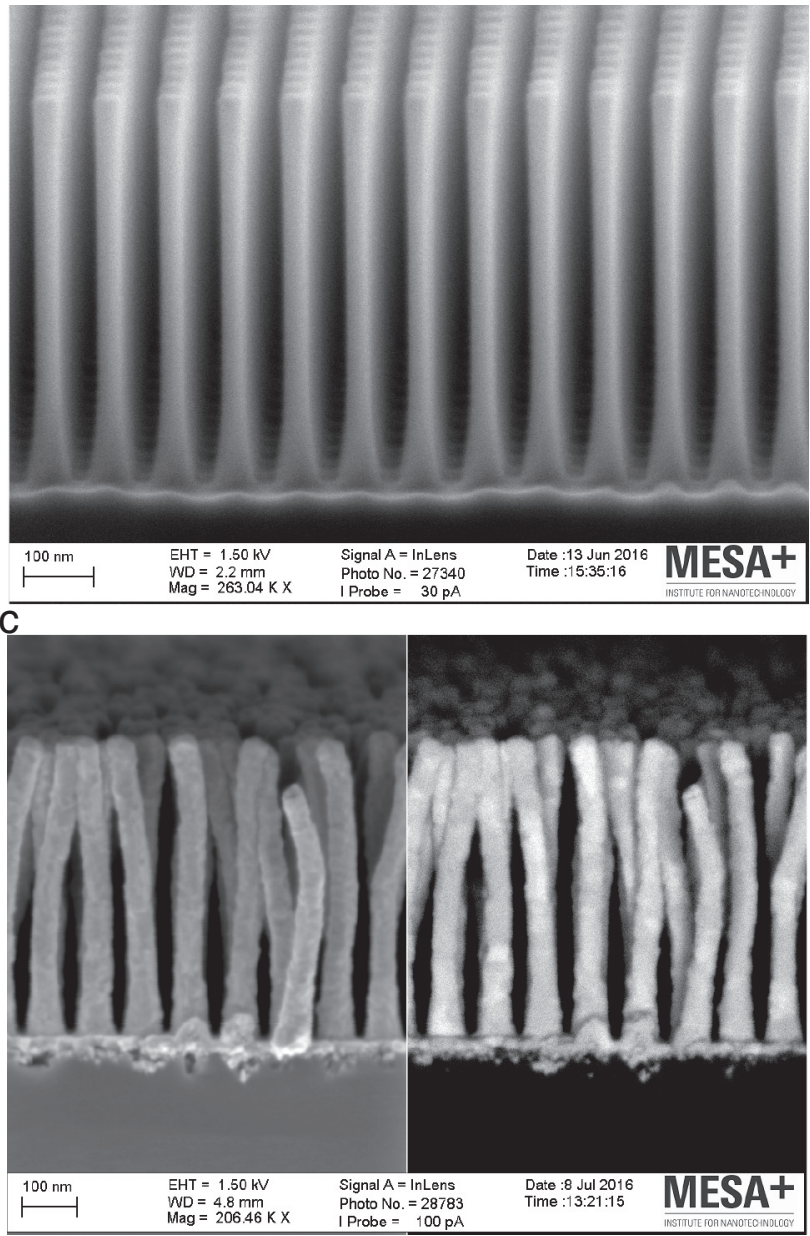

Fig. 12. (a) Growth of $\mathrm{W}$ on the reference flat $\mathrm{Si}$ substrate. The dashed line splits the $\mathrm{W}$ growth into 2 regimes (stages) due to (i) direct chemical reaction between $\mathrm{WF}_{6}$ and $\mathrm{Si}$ substrate (left) and (ii) HWALD process (right). A similar growth behavior is expected for the Si pillars. SEM images of the Si-pillar structures with an aspect ratio of 9, before (b) and after (c) the deposition of a roughly $20 \mathrm{~nm}$ of W. Both normal InLens ((c), left) and energy filtered backscattering ((c), right) images are shown.

value. As explained by H. D. Liu [47] and A. Alkhatib [48], this large disagreement can occur due to the absence of the actual current flow in case of optical measurements. Optical measurements exclude numerous electron scattering/trapping effects at the film surface and/or grain boundaries. These effects however play a crucial role during the a

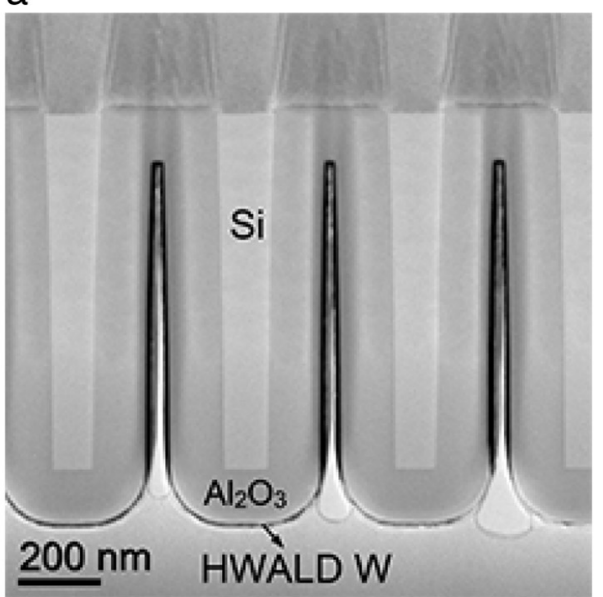

b

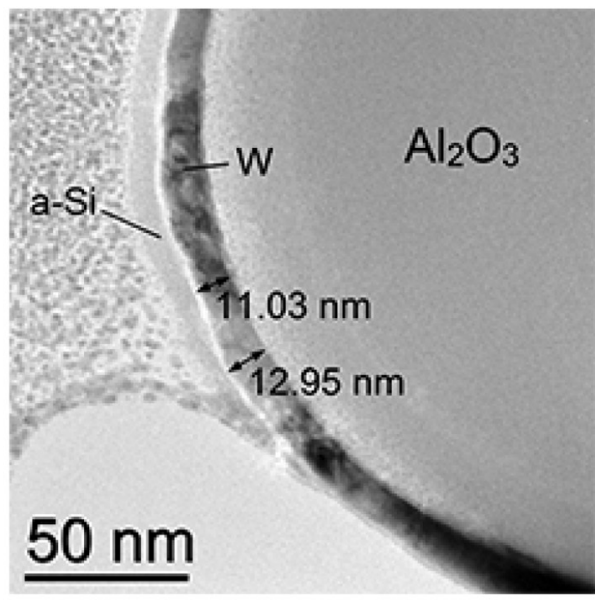

C

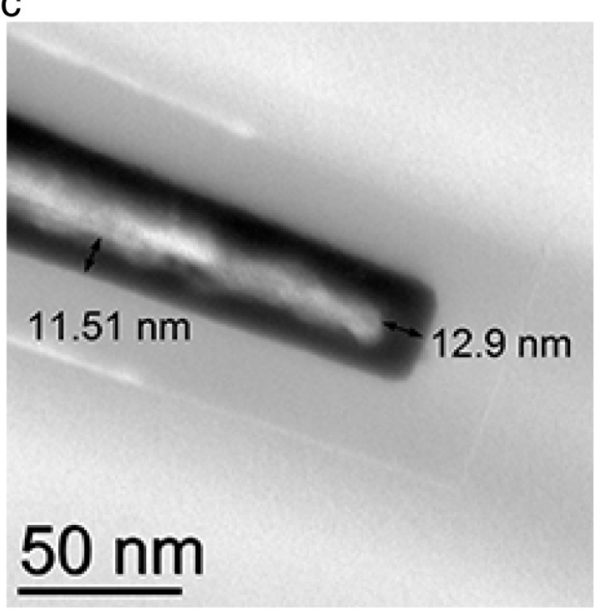

Fig. 13. (a) TEM images of a $13 \mathrm{~nm} \mathrm{~W}$ film grown by HWALD inside $\mathrm{Al}_{2} \mathrm{O}_{3}$-coated $\mathrm{Si}$ trenches. Close-ups of the top-corner and the trench-bottom are shown in (b) and (c), respectively.

physical transport of electrons under applied electric field. A decreasing film thickness leads to a significant contribution of the film surface in terms of scattering and trapping, and quantization effects may enter the stage, all increasing the resistivity. With increasing thickness, the resistivity gradually stabilizes as both the concentration of conduction electrons and their mobility approach the bulk values.

In order to evaluate film uniformity, ex-situ SE was adopted to map the resistivity and the film thickness across the wafer. As seen in Fig. 11, a $9 \mathrm{~nm}$ (measured by in-situ SE in the wafer center) HWALD film was 
examined. The average resistivity of $15.10 \pm 0.35 \mu \Omega \cdot \mathrm{cm}$ was measured, giving a variation within $4.7 \%$ across the wafer (Fig. 11 (a)). The thickness measurements revealed $9.17 \pm 0.80 \mathrm{~nm}$, or a $17 \%$ variation (Fig. 11 (b)). The thickness distribution could be related to the effect of the underlying seed layer and the surface roughness.

\subsection{Step coverage on HAR substrates}

To test the step coverage, the HWALD films were deposited on HAR $\mathrm{Si}$ pillars and in $\mathrm{HAR} \mathrm{Al}_{2} \mathrm{O}_{3}$ trenches. It was not necessary to pre-form the seed layer on Si pillars. To enable in-situ SE, a flat Si substrate was placed under the SE light spot, next to the corresponding HAR structure. In Fig. 12 (a), two growth regimes (stages) can be observed. The first regime results in the very fast growth of W up to roughly $11 \mathrm{~nm}$. Although the precursor pulses still followed the optimized recipe, the growth obviously did not occur in ALD mode. The $\mathrm{WF}_{6}$ could efficiently react with $\mathrm{Si}$ of the substrate (or Si of the pillars), forming metallic W and volatile $\mathrm{SiF}_{4}$. The role of at- $\mathrm{H}$ as a reducing agent was minimized in this regime. In the second regime, the diffusion of $\mathrm{WF}_{6}$ through the asgrown $\mathrm{W}$ became the limiting factor, shifting the film formation mechanism to the HWALD mode with a typical growth rate of $0.012 \mathrm{~nm} /$ cycle.

Fig. 12 (b) shows cross-sectional SEM images of original pillars before deposition, possessing a diameter of $30 \mathrm{~nm}$ and an aspect ratio of about 9. In Fig. 12 (c), both InLens and energy filtered backscattering images, after deposition, indicate a conformal coverage of the pillars by $\mathrm{W}$. This is visualized by the high contrast between the W layer and Si of the substrate, with the bright layer corresponding to W. After the deposition, the pillar diameter has expanded to $50 \mathrm{~nm}$. The $11-\mathrm{nm} \mathrm{W}$ formed in the first growth regime is expected to consume approx. $9 \mathrm{~nm}$ of $\mathrm{Si}$, giving a net pillar-diameter increase from 30 to $34 \mathrm{~nm}$ after the first stage. Adding $2 \times 9 \mathrm{~nm}$ to the diameter after the second stage was fairly consistent with the measured diameter expansion to $50 \mathrm{~nm}$. In addition, a layer of $\mathrm{W}(\sim 10-20 \mathrm{~nm})$ was formed at the bottom, in agreement with the total film thickness as expected from Fig. 12 (a). The pillar deformation after deposition presumably occurred due to the built-in stress.

A W layer of $13 \mathrm{~nm}$ (as measured by in-situ SE on a separate flat $\mathrm{Al}_{2} \mathrm{O}_{3}$-coated substrate placed next to the structure of interest) was further deposited into $\mathrm{Al}_{2} \mathrm{O}_{3}$-coated $\mathrm{Si}$ trenches with an aspect ratio of 36, see Fig. 13. Due to the difficult nucleation of $\mathrm{W}$ on $\mathrm{Al}_{2} \mathrm{O}_{3}$, a $\mathrm{W}$ seed layer was pre-formed as described in the Experimental section. However, thickness of the a-Si nucleation layer was limited to $0.5 \mathrm{~nm}$ only, in view of the narrow trenches. In Fig. 13 (a), one can see a uniform and conformal coverage of the $\mathrm{Al}_{2} \mathrm{O}_{3}$ surface with HWALD $\mathrm{W}$ layer all the way down to the bottom. Figs. 13 (b) and (c) shows the zoomed-in TEM images taken at different depths, clearly indicating the thickness uniformity. The average thickness of the $\mathrm{W}$ layer at the bottom (approx. $13 \mathrm{~nm}$, see Fig. 13 (c)), was very much comparable to that at the top (11-13 nm, see Fig. 13 (b)), indicating the effective ALD process and the sufficient diffusion of both $\mathrm{WF}_{6}$ and at- $\mathrm{H}$ into the trenches.

\section{Conclusions}

HWALD W films have been deposited in a home-built hot-wall reactor using $\mathrm{WF}_{6}$ gas and $\mathrm{HW}$-generated atomic hydrogen as precursors. The XPS analysis revealed high-purity films, reaching 99 at.\% of W. The fluorine signal was below the detection limit through the entire film thickness, indicating an efficient removal of $\mathrm{F}$ by at- $\mathrm{H}$. The lattice constants calculated from the XRD diffraction peak positions showed $\alpha$ phase $\mathrm{W}$. This was consistent with the $d$-spacing values of $\alpha-\mathrm{W}$ obtained from HRTEM images. Despite the differences in crystallinity between the W seed layer (amorphous- and $\beta$-phase $\mathrm{W}$ ) and the HWALD W layer $(\alpha-W)$ formed on top of it, no clear interface between these two layers could be detected, implying that the seed layer was likely turned into $\alpha$ phase $\mathrm{W}$ during the subsequent HWALD step. The resistivity measurements by means of FPP, TLM structures and the Drude-Lorentz SE model all reveal a low resistivity of $15 \mu \Omega \cdot \mathrm{cm}$ for the HWALD W. The HRTEM analysis of the films grown on HAR structures (up to 36) showed the uniform and conformal coverage, confirming the effective ALD process and the sufficient diffusion of both $\mathrm{WF}_{6}$ and at-H into deep trenches.

\section{Acknowledgments}

We thank the Dutch Technology Foundation (STW) for the financial support of this project (STW-12846). The HAR samples for HWALD of $\mathrm{W}$ are provided by ASM International.

\section{References}

[1] E. Lassner, W.D. Schubert, Tungsten: Properties, Chemistry, Technology of the Elements, Alloys, and Chemical Compounds, Springer Science \& Business Media, New York, 1999.

[2] J.D. Plummer, M.D. Deal, P.B. Griffin, Silicon VLSI Technology: Fundamentals, Practice, and Modeling, Prentice Hall, Upper Saddle River, 2000.

[3] C.H. Ting, M. Paunovic, Selective electroless metal deposition for integrated circuit fabrication, J. Electrochem. Soc. 136 (1989) 456-462.

[4] S. Rossnagel, I. Noyan, C. Cabral Jr., Phase transformation of thin sputter-deposited tungsten films at room temperature, J. Vac. Sci. Technol. B 20 (2002) 2047-2051.

[5] S.M. George, Chem. Rev. 110 (2010) 111.

[6] M. Leskelä, M. Ritala, Atomic layer deposition (ALD): from precursors to thin film structures, Thin Solid Films 409 (2002) 138-146.

[7] J. Klaus, S. Ferro, S. George, Atomic layer deposition of tungsten using sequential surface chemistry with a sacrificial stripping reaction, Thin Solid Films 360 (2000) $145-153$.

[8] J. Elam, C. Nelson, R. Grubbs, S. George, Kinetics of the WF 6 and Si 2 H 6 surface reactions during tungsten atomic layer deposition, Surf. Sci. 479 (2001) 121-135.

[9] J. Elam, C. Nelson, R. Grubbs, S. George, Nucleation and growth during tungsten atomic layer deposition on SiO 2 surfaces, Thin Solid Films 386 (2001) 41-52.

[10] S.A. Van Norman, J.W. Tringe, J.D. Sain, R. Yang, J.L. Falconer, A.W. Weimer, Using atomic layer deposited tungsten to increase thermal conductivity of a packed bed, Appl. Phys. Lett. 106 (2015) 153102.

[11] B. Kalanyan, M.D. Losego, C.J. Oldham, G.N. Parsons, Low-temperature atomic layer deposition of tungsten using tungsten hexafluoride and highly-diluted silane in argon, Chem. Vap. Depos. 19 (2013) 161-166.

[12] G. Wang, Q. Xu, T. Yang, J. Xiang, J. Xu, J. Gao, C. Li, J. Li, J. Yan, D. Chen, Application of atomic layer deposition tungsten (ALD W) as gate filling metal for $22 \mathrm{~nm}$ and beyond nodes CMOS technology, ECS J. Solid State Sci. Technol. 3 (2014) P82-P85.

[13] S.-H. Kim, N. Kwak, J. Kim, H. Sohn, A comparative study of the atomic-layerdeposited tungsten thin films as nucleation layers for W-plug deposition, J. Electrochem. Soc. 153 (2006) G887-G893.

[14] V.V. Afanas'ev, J.M.M. de Nijs, P. Balk, J. Appl. Phys. 78 (1995) 6481.

[15] M. Yang, A.A. Aarnink, A.Y. Kovalgin, R.A. Wolters, J. Schmitz, Hot-wire assisted ALD of tungsten films: in-situ study of the interplay between CVD, etching, and ALD modes, Phys. Status Solidi A 212 (2015) 1607-1614.

[16] M. Yang, A.A. Aarnink, A.Y. Kovalgin, D.J. Gravesteijn, R.A. Wolters, J. Schmitz, Comparison of tungsten films grown by CVD and hot-wire assisted atomic layer deposition in a cold-wall reactor, J. Vac. Sci. Technol. A 34 (2016) 01A129.

[17] A. Bensaoula, J.C. Wolfe, A. Ignatiev, F.O. Fong, T.S. Leung, Direct-current-magnetron deposition of molybdenum and tungsten with rf-substrate bias, J. Vac. Sci. Technol. A 2 (1984) 389-392.

[18] M.J. O'Keefe, J.T. Grant, Phase transformation of sputter deposited tungsten thin films with A-15 structure, J. Appl. Phys. 79 (1996) 9134-9141.

[19] G. Yuan, H. Shimizu, T. Momose, Y. Shimogaki, Kinetic study on hot-wire-assisted atomic layer deposition of nickel thin films, J. Vac. Sci. Technol. A 32 (2014) $01 \mathrm{~A} 104$.

[20] I. Langmuir, The dissociation of hydrogen into atoms, J. Am. Chem. Soc. 34 (1912) 860 .

[21] I. Langmuir, The dissociation of hydrogen into atoms. Part II. Calculation of the degree of dissociation and the heat of formation, J. Am. Chem. Soc. 37 (1915) 417.

[22] I. Langmuir, G.M.J. Mackay, The dissociation of hydrogen into atoms. Part I. Experimental, J. Am. Chem. Soc. 36 (1914) 1708.

[23] S. Bystrova, A. Aarnink, J. Holleman, R. Wolters, Atomic layer deposition of W1.5N barrier films for Cu metallization process and characterization, J. Electrochem. Soc. 152 (2005) G522-G527.

[24] H. Van Bui, A.Y. Kovalgin, A.A.I. Aarnink, R.A.M. Wolters, Hot-wire generated atomic hydrogen and its impact on thermal ALD in TiCl4/NH3 system, J. Solid State Sci. Technol. 2 (2013) P149-P155.

[25] A.Y. Kovalgin, M. Yang, S. Banerjee, R.O. Apaydin, A.A.I. Aarnink, S. Kinge, R.A.M. Wolters, Hot-wire assisted ALD: a study powered by in-situ spectroscopic ellipsometry, Adv. Mater. Interfaces 4 (2017) 1700058.

[26] H. Van Bui, F. Grillo, J. van Ommen, Atomic and molecular layer deposition: off the beaten track, Chem. Commun. 53 (2017) 45-71.

[27] J.E.J. Schmitz, Chemical Vapor Deposition of Tungsten and Tungsten Silicides for VLSI/ULSI Applications, Noyes, Park Ridge NJ, 1992. 
[28] G. Jellidon, F. Modine, Optical functions of silicon between 1.7 and $4.7 \mathrm{eV}$ at elevated temperatures, Phys. Rev. B 27 (1983) 7466.

[29] F. Wooten, Optical Properties of Solids, Academic Press, New York, 1972.

[30] D.K. Schroder, Semiconductor Material and Device Characterization, John Wiley \& Sons, 2006.

[31] W. Shockley, W. Hooper, H. Queisser, W. Schroen, Mobile electric charges on insulating oxides with application to oxide covered silicon pn junctions, Surf. Sci. 2 (1964) 277-287.

[32] H. Van Bui, A.Y. Kovalgin, J. Schmitz, R.A. Wolters, Conduction and electric field effect in ultra-thin TiN films, Appl. Phys. Lett. 103 (2013) 051904.

[33] B. Van Hao, Atomic Layer Deposition of TiN Films: Growth and Electrical Behavior down to Sub-nanometer Scale, Twente University Press, 2013 (Thesis).

[34] F. Allen, O. Kennard, D. Watson, L. Brammer, A. Orpen, R. Taylor, International Tables for Crystallography, vol. C, Kluwer Academic Publishers, Dordrecht, 1995

[35] R. Warncke, M.L. Gerwien, L. Gmelin, Gmelin Handbook of Inorganic Chemistry: 8th ed., No. 54, Tungsten, Suppl., Vol. A3, Springer, Heidelberg, 1989.

[36] T. Millner, A.J. Hegedüs, K. Sasvári, J. Neugebauer, Über die Bildungsbedingungen und Eigenschaften des $\beta$-Wolframs. Weiterer Beitrag zur Reduktion des Wolframtrioxyds, Z. Anorg. Allg. Chem. 289 (1957) 288-312.

[37] P. Petroff, T. Sheng, A. Sinha, G. Rozgonyi, F. Alexander, Microstructure, growth, resistivity, and stresses in thin tungsten films deposited by rf sputtering, J. Appl. Phys. 44 (1973) 2545-2554.

[38] Y. Shen, Y. Mai, Influences of oxygen on the formation and stability of A15 $\beta$-W thin films, Mater. Sci. Eng. A 284 (2000) 176-183.

[39] C. Tang, D. Hess, Plasma-enhanced chemical vapor deposition of $\beta$-tungsten, a metastable phase, Appl. Phys. Lett. 45 (1984) 633-635.

[40] W. Morcom, W. Worrell, H. Sell, H. Kaplan, The preparation and characterization of beta-tungsten, a metastable tungsten phase, Metall. Trans. A. 5 (1974) 155-161.

[41] S. Basavaiah, S. Pollack, Superconductivity in $\beta$-tungsten films, J. Appl. Phys. 39 (1968) 5548-5556.

[42] Q. Hao, W. Chen, G. Xiao, Beta ( $\beta$ ) tungsten thin films: structure, electron transport, and giant spin Hall effect, Appl. Phys. Lett. 106 (2015) 182403.

[43] A. Bartl, Fundamentals of NS-tungsten Powder Manufacture, TU Vienna, 1997 (PhD Thesis).

[44] A. Patterson, The Scherrer formula for X-ray particle size determination, Phys. Rev. 56 (1939) 978.

[45] H.E. Swanson, E. Tatge, R.K. Fuyat, Standard X-ray Diffraction Powder Patterns, U.S. Dept. of Commerce, National Bureau of Standards, Washington, D.C., 1953.

[46] H. Van Bui, A. Aarnink, A. Kovalgin, R. Wolters, Ultra-thin atomic layer deposited TiN films: non-linear I-V behaviour and the importance of surface passivation, J. Nanosci. Nanotechnol. 11 (2011) 8120-8125.

[47] H.-D. Liu, Y.-P. Zhao, G. Ramanath, S. Murarka, G.-C. Wang, Thickness dependent electrical resistivity of ultrathin $(<40 \mathrm{~nm})$ Cu films, Thin Solid Films 384 (2001) 151-156.

[48] A. Alkhatib, T. Souier, M. Chiesa, Non-ohmic transport behavior in ultra-thin gold films, Mater. Sci. Eng., B 176 (2011) 840-845. 